\title{
FILOSOFIA E COVID-19: FEUERBACH E EDGAR ALLAN POE COMO ANTÍPODAS DE UM MUNDO AVESSO À MORTE*
}

\author{
Antônio Adriano de Meneses Bittencourt ${ }^{1}$ \\ Eduardo Ferreira Chagas ${ }^{2}$
}

\begin{abstract}
Resumo:
O presente artigo discorre acerca do pensamento de Ludwig Feuerbach em articulação a um conto do famoso escritor americano Edgar Allan Poe, A Máscara da Morte Rubra, de 1842. Reflete-se aqui sobre a pretensa fixidez e cerceamento do conceito de vida, que, no mundo contemporâneo, modelado pelos vultos da razão e da religiosidade, expulsam o papel da morte como elemento fundamental através do qual se afirma a natureza em nós, sendo, aqui, denunciado como um impropério o desejo de expurgar a inexorável presença de Tânatos ( $\Theta$ óvatos) além do indício de uma postura que se transmuta moralmente em um tratamento aversivo à natureza e à vida. No mesmo, tecemos alguns comentários acerca da relação entre a crise sanitária referente à pandemia da Covid-19 e à urgência de um novo paradigma que se eleve sobre o já desgastado Antropoceno, a "Era do homem", que convulsiona ante os abusos cometidos pela humanidade em relação ao mundo natural, com destaque a uma reflexão sobre a morte como pretensão de se abrir uma senda ao possível enlace da consciência ante ao seu destino final na natureza.
\end{abstract}

Palavras-chave: Feuerbach. Poe. Morte. Crise Sanitária.

\section{PHILOSOPHY AND COVID-19: FEUERBACH AND EDGAR ALLAN POE AS ANTIPODES OF A WORLD AVERSE TO DEATH}

\begin{abstract}
:
This article discusses the thought of Ludwig Feuerbach in conjunction with a short story by the famous american writer Edgar Allan Poe, The Mask of the Red Death, from 1842. It is reflected here on the alleged fixity and restriction of the concept of life, in the contemporary world, modeled by the reason and religiosity, they expel death as a fundamental element through which nature is affirmed in us, and here, the desire to purge the inexorable presence of Thanatos ( $\Theta \dot{x} v \alpha \tau o \varsigma)$ is denounced as an insult.) in addition to the indication of a posture that is morally transmuted in a treatment aversive to nature and life. In the same, we make some comments about the relationship between the health crisis related to the pandemic of Covid-19 and the urgency of a new paradigm that rises over the already worn out Anthropocene, the "Age of Man", which convulses before the abuses committed humanity in relation to the natural world, with emphasis on a reflection on death as a pretension to open a path to the possible link of the conscience before its final destiny in nature.
\end{abstract}

Keywords: Feuerbach. Poe. Death. Sanitary Crisis.

\footnotetext{
Dedicado a meu pai e ao amigo William Abreu.

Doutorando em Filosofia - Universidade Federal do Ceará. E-mail: adriano468@yahoo.com.br.

Graduado em Filosofia pela Universidade Estadual do Ceará (UECE, 1989), Mestrado em Filosofia pela Faculdade de Filosofia e Ciências Humanas (FAFICH) da Universidade Federal de Minas Gerais (UFMG, 1993), Doutorado em Filosofia pela Universität von Kassel (KASSEL, ALEMANHA, 2002) e PósDoutorado em Filosofia pela Universität Munster (Alemanha) (2018-2019). É professor efetivo (associado) do Curso de Filosofia e do Programa de Pós-Graduação em Filosofia da Universidade Federal do Ceará (UFC) e professor colaborador do Programa de Pós-Graduação em Educação Brasileira da FACED - UFC. Coordenador do Grupo de Estudos Marxistas - GEM -, vinculado ao Eixo Marxismo, Teoria Crítica e Filosofia da Educação, e ao Programa de Pós-Graduação em Educação Brasileira da FACED - UFC. Orientador do Programa Jovens Talentos/CNPQ. Atualmente, é Pesquisador Bolsista de Produtividade do CNPQ, é membro da Internationale Gesellschaft der Feuerbach-Forscher (Sociedade Internacional Feuerbach) e dedica suas pesquisas ao estudo da filosofia política, da filosofia de Hegel, do idealismo alemão e de seus críticos Feuerbach, Marx, Adorno e Habermas. E-mail: ef.chagas@uol.com.br.
} 
“A morte é a porta da vida” (Mors Ianua Vitae) $)^{3}$. A frase, lida de modo literal, pode nos causar perplexidade, pois acreditamos paradoxal que a morte seja o início para a vida. Naturalmente, é perfeitamente compreensível se considerarmos o contexto medieval-religioso que "cunhou" tal expressão. Porém, insistindo um pouco mais nela, podemos enxergar uma maneira diversa de considerarmos a morte. Em muitos casos, a morte não é literal, mas simbólica, representando uma espécie de "passagem" ou iniciação. Em Hesíodo, a morte não figura como o fim, havendo algo como uma continuidade por meio de um tipo de pós-existência etérea. À parte o relato do grande Poeta, sempre que a morte adentra os "palácios da sabedoria humana", seu espectro desperta as mais argutas manifestações do espírito humano frente ao seu mistério.

\section{Edgar Allan Poe e Ludwig Feuerbach: Uma Reflexão sobre a Morte.}

Em A Máscara da Morte Rubra, Poe nos apresenta, com peculiar exuberância, um dos contos mais significativos acerca da indigesta teimosia humana de evitar a todos os fins o crepuscular toque da morte: enquanto as ruas serviam de abrigo aos corpos da população, a elite festejava e banqueteava-se encastelados em "segurança", um espetáculo de depravação e indiferença dignas de um mundo seccionado entre despossuídos e abastados.

Poe faz questão em descrever com minúcias o interior do castelo, o que, naturalmente, não nos cabe aqui repetir em pormenores, mas basta salientarmos sua louca suntuosidade ornada pelos delírios do príncipe Próspero: nas dependências do mesmo, sete salões que mais eram palacetes coloridos envoltos em pesados cortinais, bem como vitrais que giravam em acordo à decoração de cada sala, além de tapetes exuberantes e arabescos que representavam figuras com membros desproporcionais e toda sorte de excentricidade e volúpia estética que beiram a um gritante exibicionismo, proliferadas de uma mente fantasiosa do príncipe inebriado pelo orgulho.

A noite corria alta e o ressoar de intensidade incomum do pesado relógio a cada sessenta minutos causava nos convidados uma sensação de constrangimento, fazendo os músicos pararem no momento em que se dava o odioso tilintar das horas em um interlúdio fastidioso, porém inevitável. Contudo, algo mudaria aquela noite para sempre. Eis que, no pandemônio orquestrado pelo irremediável príncipe, surge um

3 Citação latina utilizada como epígrafe em lápides.

\begin{tabular}{|l|l|l|l|l|}
\hline Q Ronista Dialectus & Ano 10 & n. 21 & Janeiro - Abril 2021 & p. $370-381$ \\
\hline
\end{tabular}


estranho convidado, trajando uma longa mortalha acompanhada de uma máscara que reproduzia com perfeição a infortunada face de um moribundo acometido da terrível morte rubra. Introduz-se esse personagem na festa para o ofegar dos presentes que, atônitos, veem-na desfilar pelo salão, arrastando o sentimento de ira dos mascarados, acreditando tratar-se de uma brincadeira de péssimo gosto.

Tão logo o príncipe dá-se conta do maligno sortilégio provocado pela presença daquele estranho, põe-se a inquiri-lo como rispidez e, sem ser contido por nenhum dos presentes pelo tenebroso ar que inspirava, a criatura continuou seu percurso pelas salas do castelo. Ao irado príncipe, coube-lhe a honra de alçar um punhal com vistas de deter a audácia de tal invasor que já ia avançado entre os salões. Ao alcançar a indesejada figura, porém, nada mais se ouviu do que um grito e o eco do som do punhal ao cair: era a morte rubra que adentrava o castelo, seguindo-se, posteriormente, um a um, a morte dos foliões.

O conto de Poe nos dá uma bela, porém, trágica, dimensão do que resulta da insólita postura em forjar para a vida uma "zona de separação" do restante do mundo. Fatidicamente, somos sujeitos de forma incondicional a adentrar o véu de Ísis sem que esteja em nossos poderes livrarmo-nos desse destino. Por mais que se tente evitar, a morte acomete a todos, salvo que se trate de um Conde de Saint Germain, o misterioso alquimista que impressionara tanto a Voltaire como a Rousseau, e que diziam ter descoberto o elixir da longa vida. À parte esses míticos casos, os esforços em restringir o valor e significado da morte em relação à vida, terminará no destino de Tântalo: a ilusão se desfaz em cada tentativa.

Aqui se interconexiona o pensamento feuerbachiano no que concerne à questão da morte: trata-se da mais pura a afirmação da vida reconhecer a finitude do homem. Resume-se, assim, toda a sua fundamentação teórica da liberdade na natureza: é a morte ou a finitude que iguala o ser humano à natureza. Por extensão, é a natureza o limite da liberdade. Em outras palavras, é nos entendendo com a morte que apreendemos o sentido da vida.

\section{Feuerbach e a Morte}

Na obra "Pensamentos sobre a Morte e a Imortalidade" (Gedanken über Tod und Unsterblichkeit), o jovem Feuerbach ainda sob inspiração do misticismo que mais tarde irá rejeitar, nos apresenta um relato com contornos panteísticos acerca da vida, essa, 
compreendida no ciclo de morte e renascimento sem abertura para uma transcendência a qualquer plano extrassensorial. O elemento místico irrompe na figura de Deus que se manifesta no amor a partir da relação Eu-Tu.

O enfoque nessa obra aqui é assaz pertinente para nos elevarmos ao pensamento maduro do autor a respeito da morte. Consideramos que Feuerbach, ainda que divirja diametralmente nos pontos essenciais no que toca a questão da divindade (para ele, uma mera transposição de atributos naturais reunidas sob um fictício invólucro tomado como sagrado), mantém a posição que se desvela já nessa que é considerada sua primeira obra acerca do poder de absorção da vida nos limites da natureza. O frontispício dessa filosofia que encerra o fenômeno da vida nos limites do espaço-tempo, escreve seu corolário a cada linha de um novo escrito seu desde que esse polêmico texto fora publicado. Parece que o próprio Feuerbach, crendo esse ser um caminho sem volta, rompe os grilhões da modernidade e atualiza a filosofia a golpes de foice: abre-se o caminho na senda do conhecimento à revelia da autoridade e chegava-se ao fim da "modernidade clássica", como diria Engels acerca do pensamento feuerbachiano, tal como Galileu em relação ao monólogo dos medievais.

Mas, assim como Galileu que, segundo alguns, murmurou baixinho seu, no entanto, ela se move (Eppur si muove), Feuerbach fora paulatinamente silenciado do meio intelectual de sua época por trazer a vida para o plano da sensorialidade e, portanto, radicar a existência na matéria. Desde a publicação dos "Pensamentos" (Gedanken), suas reflexões foram descontextualizadas e apagadas pela tradição filosófica, sobrevivendo apenas como "um Filósofo de transição". Ora, mas é justamente a transição que evoca os mais belos exemplos de força e coragem na história do pensamento. Assim como Marx abriu caminho para se conjecturar a "insana" hipótese da luta de classes que põe em clausura os diferentes meios de domínio que se vale o homem na posse das riquezas terrestres, Feuerbach coloca ao ser humano o desafio de pensar a si como em simultânea conexão com a natureza, retrocedendo em décadas os problemas causados pela ênfase na racionalidade e no aviltamento da natureza.

No belíssimo texto do professor Eduardo Chagas, A natureza como negação da imortalidade da alma no jovem Feuerbach, já clássico no que concerne à exposição do pensamento de juventude de Feuerbach, Chagas apresenta o tema da imortalidade em Feuerbach com as seguintes palavras: 
Da doutrina da imortalidade segue, contudo, uma moralidade, que se fundamenta na representação de um outro mundo, de um além, que pressupõe uma segunda vida. Esta moralidade não corresponde à liberdade humana, que vê a si mesma na morte e reconhece nela sua ação suprema como emancipação da limitação e, por isso, como amor. (CHAGAS, 2009, p.50). ${ }^{4}$

Desse modo, a negação da morte gera um conteúdo moral que desvincula o ser da morte da morte em si, criando uma fantasmagoria que distorce a representação da morte como um limite dado. É justamente essa narrativa que povoará a mente daqueles que creem em uma possibilidade de vida após a morte e resultará na recusa do presente vivido, vida que é contada no tempo, que se destina ao recolhimento no seio do Cosmos. Cornehl ${ }^{5}$ destaca que o misticismo da obra de juventude Feuerbach, referenciado em uma apropriação dos trabalhos de Jacob Boehme, pode nos ajudar a entender mais a fundo esse problema genuinamente humano de criar uma divisa entre o pensamento e a natureza, na medida em que, pelo pensamento, o ser humano amplia sua essência para abranger todas as coisas, sejam físicas ou não. Certamente que a obra de Boehme, bastante hermética e ligada ao ocultismo ocidental, pode revelar uma senda contrária aos auspícios de Feuerbach, contudo, recuperá-lo, fazendo de Boehme um importante pensador entre os modernos, tal como Schelling e Schopenhauer o fizeram, sinaliza, além do refinado senso intelectual de pôr diferentes tradições do pensamento em diálogo, matiza a crítica feuerbachiana na medida em que põe em evidência as fontes originárias da metafísica alemã, tendo como ápice o Idealismo.

Sempre que se busca argumentos para isolar a morte da vida, cai-se no abismo da incoerência, apelando-se à alguma entidade externa que garanta o existir fora da dinâmica que atrela a mútua dependência entre os seres. Convida-se a ciência, a religião, a filosofia, e nada se consegue. Não foi à toa que um dos maiores representantes do conservadorismo ambiental, Aldo Leopold, em seu famoso texto The Land Ethic, de 1949, dissera que a religião e a filosofia não tinham "dado ouvidos" ao problema da conservação ambiental porque não foram capazes de fazer a humanidade se emancipar conscientemente de sua condição ${ }^{6}$. Leopold era um crítico do referencial abraâmico que

4 CHAGAS, E. F. A natureza como negação da imortalidade da alma no jovem Feuerbach. Princípios: Revista de Filosofia (UFRN), v. 16, n. 26, p. 35-51, 12 out. 2010.

5 CORNEHL, Peter. Feuerbach und die Naturphilosophie. Zur Genese der Anthropologie und Religionskritik des jungen Feuerbach. Disponível em: https://www.degruyter.com/view/j/nzst. 1969.11.issue1/nzst.1969.11.1.37/nzst.1969.11.1.37.xml. Acesso em: 25out. 2020, p. 69.

6 Leopold, Aldo. The land ethic. Disponível em: https://www.uky.edu/ rsand1/china2017/library/ Leopold1.pdf. Acesso em 04 abr. 2021, p. 209-210.

\begin{tabular}{|c|c|c|c|c|}
\hline Qevista Dialectus & Ano 10 & n. 21 & Janeiro - Abril 2021 & p. $370-381$ \\
\hline
\end{tabular}


desvincula a essência do homem da natureza, o qual criou o artifício da soberanidade terrestre do homem. Tal como em Feuerbach, Leopold considera paradoxal a tese de uma consideração séria sobre a importância da natureza para a vida com os ditames do credo de matriz judaico-cristã (mas que pode ser estendido para qualquer outro que legitime a ideia de que o homem possui o direito sobre a expropriação da natureza).

Sendo, portanto, a morte um "problema" para o homem no antropoceno, tratase de maquiar o destino da vida através de variados modos, fazendo da finitude um defeito, da velhice um fardo, do tempo inimigo e da morte um mal. Coincide, portanto, a negação da finitude com a negação da própria natureza, sendo preciso detê-la para que se possa viver. É preciso "abrandar" o fogo heraclitiano que germina e faz florescer para depois voltar à terra e interromper a ciclicidade da vida em prol do uso arbitrário da vontade de viver.

\section{Covid-19, Morte e Filosofia}

A pandemia do Covid-19 nos leva a sentir da pior maneira os efeitos da força da natureza sobre o homem. Ainda que não se saiba com detalhes a origem do vírus, não seria de espantar que o mesmo houvesse sido originado de algum laboratório de pesquisa avançada em pesticidas ou no desenvolvimento de uma arma química. Em qualquer das hipóteses, nada poderia reparar os milhões de vidas ceifadas. Porém, ainda que isso possa servir à ciência em termos de explicação e melhoria das pesquisas, não será essa a lição tirada ante a mais uma pandemia. É, contudo, aquilo que alcança o mais profundo sentido de estar vivo, a saber o "perigo" da morte.

A morte como consequência do vírus é tornada um "mal" não apenas porque denota o fim de uma existência, mas porque todos podem perecer. A estranha ideia de que o mal não atinge apenas uns poucos ou muitos (que, para alguns, bem que poderia acometer apenas aqueles povos oriundos dos lugares mais pobres), causa um terror generalizado. Aqui não há separação entre ricos e pobres, tal como no conto de Poe. O nefasto microrganismo não dissocia os que possuem caros planos de saúde e gordas contas bancárias de mendigos e indigentes. Esse, ainda que duro, é um ensinamento de grande valor.

Se é preciso ter uma postura consciente diante da vida, sabendo-se do perigo em se manipular uma série de potenciais microrganismos patogênicos a preço de qualquer arbítrio da vontade, porque não ter uma consciência da morte ao se fazer o mesmo? 
Brinca-se com a vida a cada novo invento e esquece-se de preparar o homem a uma saudável e consciente avaliação de sua condição finita. Sem educar o homem para a morte, a vida mantém-se ao homem como a única faceta digna de consideração, no desejo de uma nova "fórmula" que lhe prolongue os dias e lhe conceda a maximização do gozo sobre a terra. Como nos diz Feuerbach, a imagem do homem moderno, esboço ao "incompleto" contemporâneo, é um mero fantasma. ${ }^{7}$

A pandemia, assim, oferece aos filósofos a oportunidade de refletir sobre o destino do homem, não aureolado de floreios metafísicos, mas reconhecendo o quão longe estamos de uma filosofia que afirme a vida. Não é imoral reconhecer as necessidades essenciais do homem, bem como não é vulgar dar-lhe um fármaco filosófico que o permita se ver no mundo como homem, dependente da natureza e do outro ${ }^{8}$. A vaidade e a soberba com que as abstrações teológicas, científicas e filosóficas confinaram a intelectualidade oficial é um velado manifesto do cinismo que dissimula a integralidade do fenômeno da vida. O intelectual é um simulacro de homem. A teoria um simulacro da natureza.

Porém, alguém poderia salientar ser a Covid-19 uma questão meramente do âmbito da técnica. Será mesmo? Ao mesmo tempo que se avoluma o número de casos, aumentando os gastos e a logística implicada para atender a demanda populacional, desvela-se como um problema da técnica. Por outro lado, a parte não-contaminada fica em casa ansiosa com o risco de contágio. Diversas pessoas relatam depressão, instabilidade emocional, e toda espécie de desconforto psicológico decorrente do risco de morte a que expõe a infecção pelo vírus. Esse quadro, que só podíamos fazer ideia através da ficção, que expunha através de produções cinematográficas as ansiedades dos campos de batalha e o iminente perigo de aniquilação, hoje é vivido por centenas de pessoas no interior de suas casas (se é que moram em uma), frente a um mundo que não conheciam ou que ignoravam. Claramente se vê que não é apenas uma questão técnica, mas envolve a sensibilidade, a corporeidade, enfim, a morte, revelando-se como um problema humano.

A ideia de um grande número de pessoas contaminadas por algum mal não é alheia aos tempos atuais e quase sempre se noticiam tais coisas de países cujo o índice de

7 FEUERBACH, L. Princípios da Filosofia do Futuro. Disponível em: http://www.lusosofia.net/textos/feuerbach_ludwig_principios_filosofia_futuro.pdf. Acesso em: 06 set. 2020 , p. 62.

8 "A relação moral e racional do homem com o estômago não consiste, pois, em lidar com ele como ser bestial, mas como ser humano. Quem faz terminar a humanidade no estômago, rejeita o estômago para a classe dos animais, autoriza o homem a comer como uma besta". (Ibidem, p. 72).

\begin{tabular}{|l|l|l|l|l|}
\hline Q Rovista Dialactus & Ano 10 & n. 21 & Janeiro - Abril 2021 & p. 370 - 381 \\
\hline
\end{tabular}


desenvolvimento humano é abaixo do mínimo estabelecido pelos órgãos oficiais. Até que nossos encastelados palácios não sejam atingidos (e aí podemos incluir toda a porção desenvolvida do mundo ocidental), convivemos como os foliões do baile do conto de Poe.

O espanto provocado pela difusão e rápido contágio da pandemia, a fragilidade da vida diante da morte serve-nos ao catártico exercício de considerar a vida em sua totalidade, tal como nos adverte Feuerbach com sua filosofia do futuro. Fazer uma filosofia para os vivos, é convidar todos ao desafio de emancipar-se conscientemente sabendo-se vivos, e não encimados artificialmente pelas "gruas" da arrogância paternalista que execrou a natureza e destituiu sua indiferença com relação à hierarquia dos seres, proclamando o direito do homem sobre a terra. Ainda que o homem seja o mais desenvolvido culturalmente através de suas obras, não está ele autorizado ao "açoite" à natureza, escravizando e explorando seus seres e recursos sob o pretenso papel de herdeiro que outorga.

É estranho que um pensador que tenha levantado tantas questões profundas que emergem com o desdobramento do excessivo uso da razão do ocidente tenha sido tão pouco lido e interpretado de modo sério. Serrão ${ }^{9}$ considera completamente indiferente o fato de que a linguagem hoje utilizada no âmbito das discussões ambientais não seja conhecida por Feuerbach. Essa ideia apenas reforça que o pensamento do Filósofo não se situa em sua época. Não quis ele seguir as conclusões do seu antigo professor e, assim, terminar como um exegeta que figura em "notas de pé de página" em textos sobre Hegel ou sobre o hegelianismo. Ao contrário, muito claramente Feuerbach se afirma como um pensador póstumo, abrindo caminho para uma futura geração de pensadores que inclui figuras da mais alta estirpe intelectual europeia, como Marx e Nietzsche.

O que se enleva de sua filosofia é a organicidade do todo, uma ideia que se desenvolve no misticismo boehmista-schellinguiano, mas que é trazido à concreção por Feuerbach. Sem considerarmos nosso lugar na natureza, nossa irmandade com outros seres e, assim, vida e morte como uma só coisa, isto é, como contrários que se afirmam e se negam, que se desejam e se repelem, para utilizar um jargão místico, nossos pés estarão fora do desafio de viver. Viver sem morrer é uma condição do pensamento, não da natureza ${ }^{10}$.

9 SERRÃO. A. V. O Habitar Ético na Natureza: Segundo Ludwig Feuerbach. Revista Portuguesa de Filosofia, T. 59, Fasc. 3, Filosofia e Ecologia: Elementos para uma Ética Ambiental pp. 689-711, jul. set. 2003. Disponível em: https://www.jstor.org/stable/40337760. Acesso em 22 de jan. 2020, p. 711.

10 A tarefa da filosofia e da ciência em geral consiste, pois, não em se afastar das coisas sensíveis, isto é, efetivas, mas em ir até elas - não em transformar os objetos em pensamentos e em representações, mas

\begin{tabular}{|l|l|l|l|l|}
\hline Q Ronista Dialactus & Ano 10 & n. 21 & Janeiro - Abril 2021 & p. $370-381$ \\
\hline
\end{tabular}




\section{Conclusão:}

Tal como os foliões do castelo do infeliz príncipe Próspero, que acreditaram encontrar nas dependências daquele um modo de estabelecer uma fronteira diante do restante do mundo, o homem "civilizado" faz sobreviver o desafio posto aos magos e ocultistas de séculos passados para encontrar um antídoto capaz de vencer a morte. Feuerbach enunciou, à revelia dessa postura que desencoraja a empresa sincera em considerar-se finito, um projeto emancipatório que rejeita os "suntuosos poderes" verbais que, da loucura dos filósofos, tal como do príncipe de Poe, reverberavam os lampejos de uma realidade particular, ensimesmada, entulhada nos recônditos vazios da especulação, servindo de deleite apenas aos que negavam conscientemente a força da natureza sobre a vida.

De um modo inexorável, no entanto, a natureza sempre vence e aclara nosso despreparo frente à sua fortuita visita, seja através da vida ou da morte. O desafio posto por Feuerbach de fundar uma filosofia do homem com inclusão da natureza, nada mais é do que um eufemismo sabiamente reconhecido por Feuerbach que não dissocia em origem as duas coisas. Qualquer filosofia que se pretenda com honestidade prover à humanidade um Pharmakós para alma do homem, tal como o quis Epicuro, deve aceitar como parte dessa tarefa considerar a morte como algo a que não se deve evitar às custas de "afagar" a ilusão da eternidade do homem.

$\mathrm{Na}$ articulação entre o texto de Poe e a filosofia de Feuerbach, quisemos demonstrar que, poeticamente figurando sobre trajes horrendos, a figura da morte rubra, deslizando sobre as salas do aferrolhado castelo, nos serve de analogia aos igualmente trancafiados porões da consciência humana que buscam evitar a natureza a todos os custos, assemelhando-se a um recôndito decorado pela mais espalhafatosa quinquilharia de ideias como pretexto para encontrar para o homem uma posição que o mantenha cindido de sua verdadeira essência, a saber, de sua corporeidade, de sua naturalidade, de sua condição de finitude e de morte.

Quando se apresenta o pensamento de Feuerbach nas obras costumeiramente tratadas desse autor, não podemos atentar plenamente à real dimensão que se situa por trás de seus apelos em favor de uma humanidade livre dos grilhões da classe sacerdotal/intelectual que empurra ao homem um modelo de moralidade que artificializa

em tornar visível, objetivo, o que é invisível para os olhos comuns. (FEUERBACH, L. Princípios da Filosofia do Futuro. Op. cit., p. 62).

\begin{tabular}{|l|l|l|l|l|}
\hline Romista Dialectus & Ano 10 & n. 21 & Janeiro - Abril 2021 & p. $370-381$ \\
\hline
\end{tabular}


a si próprio, bem como a suas relações. Vivendo na ignorância de sua finitude, não é difícil encontrar os meios que conduzem a humanidade a fazer da natureza uma escrava, uma palavra que, empregada aqui no sentido em que fora conhecida no contexto do tráfico negreiro para as américas, ilustra com perfeição a imagem fictícia em que se deu o avanço da racionalidade no ocidente, a saber, como estupro e adoecimento da terra.

Nota-se na articulação supracitada o contraste que os autores aqui selecionados apresentam a seu modo entre a vontade de gozo permanente da vida e o esquecimento de que não se está em parte alguma fora da natureza. O miasma, portanto, desse diálogo secreto que figura entre os outros, nos dá os indícios de uma postura que confirma o fantasmagórico ser que tomou forma no séc. XX sobre os auspícios do "novo homem". Ora, na contramão de tudo, o que se viu foi uma humanidade à beira de um perigo real de extinção, totalmente cega em sua marcha, em êxtase pelas conquistas sobre terra, mar e espaço e, tal como os convidados que dançavam perfeitamente ignorantes daquela inesperada visita, o homem da tecnocracia se vê perplexo quando o mundo perscruta seus aposentos desafiando seus protocolos de segurança, como se dá no descontrole e na falta de preparo ao lidar com os avanços dessa infeliz e difícil crise sanitária.

É preciso tornar viva a filosofia não apenas como uma disciplina entre tantas, mas no sentido em que ela constitui um esforço para se manter os "olhos abertos" aos problemas do mundo. O "pesado" soar do relógio que insiste a cada hora em "retirar a tranquilidade" dos presentes do fatídico baile pode ser visto como uma lembrança do tempo, de sua insistente e involuntária presença da qual nada na natureza prescinde. Uma filosofia de tempo e espaço reais, como Feuerbach a quis, situa o homem no "pórtico" que leva aos "novos salões" da vida, com rijas colunas que, ao adentrar-se, promove o reencontro do homem consigo, reconciliado com sua essência.

Por fim, recorrendo outra vez ao mito de Tânatos na poesia de Hesíodo, que ela, a morte, possa servir como uma "iniciação", para a maturidade intelectual dos seres humanos, mas, aqui, não nos termos de uma compreensão mística ou da experiência esotérica, mas por onde se viabiliza a oportunidade de ver seu aspecto contrário e, por isso, complementar, a vida, simbolizada como um semicírculo a ser completado por sua irmã na roda da existência integral.

\section{Referências}

\begin{tabular}{|l|l|l|l|l|}
\hline Rovista Dialactus & Ano 10 & n. 21 & Janeiro - Abril 2021 & p. 370-381 \\
\hline
\end{tabular}


ARIÈS, Philippe. A história da morte no ocidente: da idade média aos nossos dias. Rio de Janeiro: Ediouro, 2003.

BOEHME, Jacob. A revelação do grande mistério divino. São Paulo: Polar Editorial, 1998.

BRANDÃO, Junito de Sousa. Dicionário mítico-etimológico. Petrópolis, Rj: Vozes, 2014.

CHAGAS, E. F. A vontade é livre? Natureza e Ética em Ludwig Feuerbach. Disponível em http://www.revistadialectus.ufc.br/index.php/RevistaDialectus/article /view/208. Acesso em 10 ago. 2020.

CHAGAS, E. F. A natureza como negação da imortalidade da alma no jovem Feuerbach. Princípios: Revista de Filosofia (UFRN), v. 16, n. 26, p. 35-51, 12 out. 2010.

CORNEHL, Peter. Feuerbach und die Naturphilosophie. Zur Genese der Anthropologie und Religionskritik des jungen Feuerbach. Disponível em: https://www.degruyter.com/view/j/nzst. 1969.11.issue1/nzst.1969.11.1.37/nzst.1969.11 .1.37.xml. Acesso em: 25out. 2020.

ELIADE, M. História das crenças e das ideias religiosas I- da idade da pedra aos mistérios de elêusis. Rio de janeiro: Zahar, 2010.

FEUERBACH, L. Pensamientos sobre muerte e inmmortalidad. Madrid: Alianza Editorial, 1993.

FEUERBACH, L. Preleções sobre a essência da religião. Tradução de José da Silva Brandão. Petrópolis, RJ: Vozes, 2009.

FEUERBACH, L. Princípios da filosofia do futuro. Disponível em: http://www.lusosofia.net/textos/feuerbach_ludwig_principios_filosofia_futuro.pdf. Acesso em: 06 set. 2020.

GREY, W. Anthropocentrism and Deep Ecology. Disponível em: https://www. researchgate.net/publication/233354056_Anthropocentrism_and_Deep_Ecology.

Acesso em 19 de nov. 2020.

HEIDEGGER, M. Ensaios e conferências. Petrópolis: Vozes, 2002.

Leopold, Aldo. The land ethic. Disponível em: https://www.uky.edu/ rsand1/ china2017/library/Leopold1.pdf. Acesso em 04 abr. 2021.

MOSCOVICI, S. Natureza: para pensar a ecologia. Rio de Janeiro: Mauad, 2007.

ORGANIZAÇÃO PAN-AMERICANA DA SAÚDE. Folha informativa sobre COVID-19. Disponível em https://www.paho.org/pt/covid19. Acesso em 20 mar. 2021.

POE, Edgar Allan. Histórias extraordinárias. São Paulo: Companhia das Letras, 2008. 
SERRÃO. A. V. O Habitar Ético na Natureza: Segundo Ludwig Feuerbach. Revista Portuguesa de Filosofia, T. 59, Fasc. 3, Filosofia e Ecologia: Elementos para uma Ética Ambiental pp. 689-711, jul. - set. 2003. Disponível em: https://www.jstor.org/stable/40337760. Acesso em 22 de jan. 2020.

WOLGAST, Sigfried. Deus sive natura: Zum Pantheismus in der europäischen Philo sophie-und Religionsgeschichte. Disponível em: https://leibnizsozietaet.de/wpcont ent/uploads/2012/10/01_wollgast1.pdf. Acesso em 23 out. 2020. 